\title{
Research and Analysis on Reading by College Students in the Era of Mobile Reading
}

Xie Weiguo

Library of Zhongyuan Universiy of Technology

Abstract: With the increasing advancement and popularity of electronic media, traditional reading mode and book purchase means have been updated and upgraded. As a big consumer of books, the college student group plays a double- complementary role in the marching force that drives this "revolution". When the habit of holding a book and reading it at night is replaced by web-based virtual environment, readers have sharply recognize such trend, the internet has changed the perception of people on the time-space relationship. It causes changes in the "relationship among human beings". The characteristics of untouchable mode for the internet will really impact the daily life of the general public and event invoke our multi-dimension thinking of individuals themselves and external environment. The internet is promoting "him" and "them" to get close to each other with an invisible force and the reading trend of internet literature is emerging gradually.

Keywords: mobile reading era, college student, reading research, analysis

Published Date: January 2018

Published Online: $31^{\text {st }}$ January 2018

\section{Status and behavioral characteristics of college students' mobile reading}

In recent years, mobile reading is widely used in the college campus. Students especially prefer the characteristics of internet such as openness, interaction, novelty, personalization and diversification. Internet reading has become an important activity indispensable to them. The source of knowledge learnt by students is no longer limited in books and what teachers impart. As an informal pathway for learning, mobile learning is progressively liked and accepted by students. According to the interviews with domestic colleges and universities and the findings of empirical sample surveys, e-reading and paper reading are complementary to each other for college students in the time for reading and the amount of reading. Ereading bears the stretching function of paper reading. Prices, operating convenience and reading experience are the main factors that have an influence in the selection of college students on electronic devices. The main way for mobile reading is through short message reading, online reading via WAP sites and reading via mobile clients. Compared with paper reading, mobile reading is focused on news information, electronic newspaper, electronic periodicals, video resources, audio books and network novels among college students.

Due to limits on economic abilities, college students are more apt to use free electronic resources in various portals on the internet and secondarily digital resources offered by libraries in colleges and universities, such as e-books and electronic periodicals. For the learning of expertise, paper reading is still a main way of reading for college students and an approach to acquire knowledge on a deep level. Only $9 \%$ of college students search information for the "needs of learning", with reading contents including journal papers, expertise, research reports, Baidu Wenku etc.

Phenomena like superficial reading and fragmented reading exist in college students' mobile reading on a large scale. Due to limitations on mobile reading, "reading network" is not able to form deep thinking and knowledge and thus cannot take the place of professional books. The functions of college students' mobile reading for learning and capacity training are weak, which means college students 
have deficiencies in correct utilization of learning functions of network and need guidance. For libraries in colleges and universities that directly offer service in college students' mobile reading, how to correctly lead them to improve mobile reading quality is an issue worth attention and deep research.

\section{Selection and confusion of college students in the times of mobile reading}

First, the consumption selection of classic reading and best-selling books is involved in the possibility of classic value being overlooked and even dispelled. In campuses, the behavior of reading pure literary texts appears exceptional. Particularly, modern literature, which led the development and growth of concepts of new literature in the first half of the20th century, is considered as an antique-class reading material. Due to the specialty of its social background, new modern literature is built within the cultural category of essential intellectuals with consciousness of foresight. When western civilization enters China aggressively, new modern literature is much distinctly different from traditional works in terms of discursive power and ideological tension of creators. New modern literature is more open and tolerant and by contrast, traditional works are more introversive.

Now reading these kings of works is a task of college students majoring in Chinese. At the present time when everyone can become a writer, some network literature works are no longer mainly aimed at social functions of carrying the mission of the era but leisure and recreation. Relax and disordered creation access system leads to chaos and poor quality in books on the market, which, in addition to overstated, colorful and eye-catching covers, essentially imitate and reproduce others with restraint so that people can't help lamenting the lack and inferiority of imagination of nowadays' authors after reading

Second, when pure literary texts and practical books lure readers to make consumption choice, pure literary texts also lack real competitiveness. It seems that only offering keys to success in life straightforward can cause general reader to exchange corresponding market costs for unknown wealth returns.

As knowledge capital becomes increasingly important, many literati, scholars and even officials enter the capital market and turn into an elite in the business world, with the help of huge exploration of knowledge energy, and then summarize the successful cases of transforming their knowledge capital into wealth, giving arise to a mythological mode of entrepreneurship that draws public attention instantly. In the most prominent position at the book mall, these kinds of works have kept closely up with youth literature and become an effect and a brand with most consumption appeal. For the youth who struggle in the workplace, these types of articles can even stimulate the purchasing desire of readers. As a result, when it comes to the limited expenditure and distribution of spiritual products, how the quality is not the only criterion for selection.

Finally, the thinking way and cognitive perspective of utilitarianism cause young readers to give up literature classics books that seem "useless" when they make choices to buy books. As a dominant consumer group in the book market, readers at aged between 20 and 30 surprisingly and deliberately keep a cultural and psychological distance from classics. Young readers can identify the mix in the cultural consumption situation, but when all value systems are measured by the amount of wealth as a chip, general readers have to confront the comparison between the soul and money, which layer of space the reading is taken to at last is not simply dependent on reading itself.

Pragmatism, utilitarian pursuit and even rising to fame overnight in haste have been the purpose and principles of learning for many young people. They are not defying the cultural texture of classics or too obtuse to understand that the richness of a culture requires many years of digestion and introspection, but they fail to give classic texts a quiet reading space. Just because of this, writers like Ba Jin seem less significant in front of readers with a fast-fooddoctrine-oriented reading attitude, and even so insufficient that these readers do not want to read 
their books once again.

\section{Service mode of college libraries in the context of mobile reading}

\subsection{Establish and constantly enhance the idea of serving readers}

For reading in the mode of mobile reading, the content and form of service have change compare to the previous ones, but the idea of service has not changed and it is still that trying hard to offer reader services is needed. Moreover, the idea even should be continuously improved in the mode of mobile reading. Of course, it is not possible to serve reader face to face when mobile reading is applied. At this point, it is advisable to strengthen the management of the service personnel, regain the service idea of "Reader First" deeply in the mind of each service person, learn related service knowledge and improve our accomplishment so that readers can enjoy thoughtful services even when they read books on mobile devices or other reading devices.

\subsection{Strengthen propaganda and train users of mobile libraries}

Many college students have insufficient understanding of the importance of mobile reading and complex and massive information on the network offer college students a broad platform in reading, but lots of college students are not able to find information resources suitable for them. Investigations show college students spend a great deal of time and efforts in searching and reading ineffective and useless information. Entertaining and fast-food type reading takes up most of reading time and the mobile reading efficiency of college students is very low. If things go on like this, students easily form a bad habit of being out of mine and fickle while wasting precious resources. College libraries should intensify publicity efforts, introduce related knowledge of mobile libraries to new students when they enter the university, allow every college student to get familiar with and understand the value of mobile libraries to learning and scientific research and let more college students learn about mobile reading through online publicity in library websites and WeChat public platforms or offline means such as lectures of library staff, organization of mobile reading quiz and description of school publications, and form a good reading habit of utilizing digital resources in mobile libraries.

\subsection{Enhance the construction of mobile reading resources}

Resource construction is the fundamental of innovation in mobile reading services of college libraries. Without high-quality resources that meet the needs of college students in learning and scientific research, mobile reading will be less productive. Mobile reading not only transfers digital resources to the mobile reading platform, but deeply process and sort digital resources, and offer highquality reading services to students with different needs selectively with emphasis. For example, colleges leave many precious excellent resources and practical training videos etc. in teaching and scientific research activities. These resources have high learning values. Libraries can organize them for college students to read and view on mobile devices. In addition, with weak spending power, college students tend to choose plain-text, low-traffic resources and seldom read some high-resolution video resources. Therefore, college libraries should compress and convert some high-traffic teaching videos with compress technologies without affecting viewing for students to read. Colleges can also build a wireless local area network in the fixed area in the campus to reduce mobile reading costs for students.

\subsection{Actively introduce new technology to expand services}

The mature and development of new media technology provide mobile reading in college libraries with an opportunity of development. Mobile libraries can introduce computer technology to develop personalized service, such as introducing RSS, TAG, WIKI, QQ, WeChat etc. in to mobile libraries to improve the effect of service. Take WeChat as an example, currently almost every college student installs WeChat on their mobile 
device. WeChat becomes a main medium for college students to chat, make friends and browse news and also offer an excellent platform for mobile reading services of college libraries. Libraries can apply for a WeChat public account, post various activities they hold, describe the latest literature resources and most popular books of libraries, launch activities of voting for your favorite books and cite students whose performance is outstanding, on the WeChat public platform, so as to correctly guide and encourage student for high-level reading and create a strong reading atmosphere. Besides, libraries can also realize real-time communication and exchange with student through WeChat platform to understand the recommendations of college students on their mobile reading service, and thus make improvements in mobile reading contents and approaches to meet the read requirements of college students.

\subsection{Form a professional service team}

After mobile reading is implemented, still letting previous library service personnel serve is not feasible, the demands of people have changed and corresponding services have changed too. Therefore, to offer readers better service, libraries must build a team specially designed for online service, and on the other hand, libraries then will consider their management capacity, hence in the process of library management, it is advisable to divide them into three levels based on their work ability. Those with normal ability are a general employee, those with certain professional competences are a professional employee, and those who know more and are active and advanced in thought are a senior employee. Then they will be assigned related tasks. For general library staff, what they should do is to investigate what requirements reader have in the reading process, then classify these requirements into server categories according to designated standards. For some simple requirements, the general staff can solve them. But for some difficult requirements, the general staff can leave them to senior staff. General staff actually just solve some simply problems. Professional staff has certain expertise themselves, so they can help general staff resolve difficult work after finishing their own work. In short, with the development of information technology and changes in reader requirements, mobile reading mode emerges, constantly develops and will eventually become one of main reading forms for readers; therefore, to meet the requirements of readers, it is a must to enhance related online services.

\section{References}

[1] Ye Shengwei. A study on the status and strategies of college students' "micro reading" [D]. Chongqing University of Posts and Telecommunications, 2016

[2] Mei Xiuxiu, Qin Ping, Li Xuechen. A study on the status and promotion of college student reading in the times of new media[J]. Information Research, 2016, (04):62-66.

[3] Wang Jianhong. Correlation and innovation of reading promotion of college students in the context of social network[J].Journal of The Sichuan Society for Library Science, 2016,(02):63-66.

[4] Shi Yanhui.An empirical study on factors affecting the socialized reading behaviors of college students [D]Qufu Normal University, 2016.

[5] Huang Tianyi. A study on extracurricular reading tendency of comtemporary college students [D]. Jiangsu University,2016

[6] Wang Jia. A study on the influence of mobile reading in the learning habit of college students [D].Shanxi Normal University, 2016

[7] Zhang Dan. A study on the formation of reading habits of college students [D].Liaoning University of Technology, 2016 